\title{
PENGELOMPOKAN KABUPATEN/KOTA DI PULAU JAWA BERDASARKAN FAKTOR-FAKTOR KEMISKINAN DENGAN PENDEKATAN AVERAGE LINKAGE HIERARCHICAL CLUSTERING
}

\author{
Sri Wahyuni' ${ }^{1}$, Yogo Aryo Jatmiko² \\ Badan Pusat Statistik \\ e-mail: ${ }^{1}$ swahyuni@bps.go.id
}

\begin{abstract}
Abstrak
Pulau Jawa masih merupakan pulau dengan persentase penduduk miskin terbesar di Indonesia. Dalam menentukan kebijakan penanggulangan kemiskinan, perlu diperhatikan faktor-faktor yang mempengaruhi kemiskinan.Selain itu, kemiskinan di setiap wilayah memiliki karakteristik yang berbeda, sehingga perlu adanya pengelompokan wilayah agar kebijakan yang akan dilaksanakan tepat sesuai dengan karakteristik wilayah. Tujuan dari penelitian ini adalah mengelompokkan kabupaten/kota di Pulau Jawa berdasarkan faktor-faktor kemiskinan tahun 2017 dengan pendekatan average linkage hierarchical clustering. Faktor-faktor kemiskinan yang digunakan sebagai dasar pengelompokan adalah tingkat pengangguran terbuka, persentase rumah tangga yang bekerja di pertanian, pengeluaran rumah tangga per kapita, dan rata-rata lama sekolah. Hasil penelitian menunjukkan ada dua kelompok wilayah kabupaten/kota di Pulau Jawa. Kelompok pertama, terdiri dari Kota Jakarta Barat, Kota Jakarta Selatan, Kota Jakarta Timur, Kota Surabaya, Kota Jakarta Pusat, Kota Malang, Kota Bandung, Kota Yogyakarta, Kota Jakarta Utara, Kota Depok, Kabupaten Bantul, Kota Salatiga, Kota Tangerang Selatan, Kota Madiun, Kabupaten Sleman, Kota Bekasi, Kabupaten Sidoarjo, Kota Semarang, Kota Tangerang, Kota Surakarta. Sedangkan sebanyak 99 kabupaten/kota lainnya masuk dalam kelompok kedua. Kelompok pertama merupakan kota-kota besar di Indonesia yang tingkat kemiskinannya rendah, sedangkan kelompok kedua sebagian besar terdiri dari kabupaten/kota yang dicirikan dengan wilayah perdesaan yang tingkat kemiskinannya tinggi.
\end{abstract}

Kata kunci: Pulau Jawa, faktor kemiskinan, average linkage hierarchical clustering

\begin{abstract}
Java is still an island with the largest percentage of poor people in Indonesia. In determining poverty reduction policies, it is necessary to consider the factors that influence poverty. Moreover, poverty in each region has different characteristics, so there needs to be regional grouping so that the policies that will be implemented are in accordance with the characteristics of the region. The purpose of this study is to classify regencies in Java based on poverty factors in 2017 with the average linkage hierarchical clustering approach. The poverty factors that are used as a basis for grouping are level of open unemployment, percentage of agricultural households, household expenditure per CAPIta, and mean years schooling. The results showed that there were two groups of regencies in Java. The first group, consisti of West Jakarta City, South Jakarta City, East Jakarta City, Surabaya City, Central Jakarta City, Malang City, Bandung City, Yogyakarta City, North Jakarta City, Depok City, Bantul Regency, Salatiga City, South Tangerang City, Madiun City, Sleman Regency, Bekasi City, Sidoarjo Regency, Semarang City, Tangerang City, Surakarta City. Whereas 99 other regencies were included in the second group. The first group is large cities in Indonesia with a low poverty rate, while the second group consists mostly of districts / cities characterized by rural areas with high poverty levels.
\end{abstract}

Keywords: Java Island, poverty factor, average linkage hierarchical clustering 


\section{PENDAHULUAN}

\section{Latar Belakang}

Kemiskinan masih menjadi isu dunia karena jumlahnya yang besar dan dampak yang ditimbulkannya sangat buruk bagi kehidupan masyarakat. Sejak 25 September 2015, seluruh masyarakat dunia secara resmi berkomitmen untuk melaksanakan Agenda 2030 yang tersaji dalam Tujuan Pembangunan Berkelanjutan atau Sustainable Development Goals (SDGs) yang terdiri dari 17 tujuan dan 169 target. Dalam SDGs, penanggulangan kemiskinan menjadi tujuan pertama target pembangunan. Target yang ingin dicapai adalah mengakhiri kemiskinan dalam segala bentuk dimanapun.

Keseriusan pemerintah dalam upaya mencapai target penurunan kemiskinan tercantum dalam Rencana Pembangunan Jangka Menengah (RPJM) 2015-2019 yang menunjukkan bahwa salah satu visi pembangunan nasional adalah mempercepat pemerataan dan keadilan (Bappenas, 2014). Menurut Badan Pusat Statistik (2018), jumlah penduduk miskin di Indonesia diperkirakan sebesar 26,58 juta orang atau sekitar 10,12 persen dari total penduduk pada tahun 2017. Dari total ini sekitar 52 persen penduduk miskin berada di Pulau Jawa. Fenomena semacam ini mengindikasikan bahwa strategi pengentasan kemiskinan yang telah diterapkan belum mampu menciptakan pemerataan pendapatan (redistribution of income), mengatasi ketimpanganketimpangan serta mengurangi kemiskinan, terutama di Jawa. Problematika kemiskinan yang dialami masyarakat Jawa merupakan penghambat bagi upaya peningkatan kesejahteraan penduduk. Hal ini disebabkan oleh pelbagai sisi sosial budaya dan ekonomi yang melekat pada kondisi kemiskinan itu sendiri yang disebut sebagai lingkaran setan kemiskinan (vicious circle of poverty).

Untuk merancang penanggulangan kemiskinan harus memperhatikan beberapa aspek di setiap wilayah. Aspek-aspek tersebut mencakup aspek sosial, ekonomi, budaya, politik serta aspek waktu dan ruang. Faktor-faktor penyebab kemiskinan perlu terlebih dahulu diketahui agar strategi penanggulangan kemiskinan sesuai dengan kondisi masyarakat di setiap wilayah. Tujuan dari penelitian ini adalah melakukan pengelompokan kabupaten/kota di Pulau Jawa yang didasari adanya faktor-faktor kemiskinan agar program pengentasan kemiskinan menjadi lebih terarah, efektif dan tepat sasaran. Bararakbah dan Arai (2004) menyebutkan metode pengelompokan yang baik adalah metode yang mempunyai nilai simpangan baku dalam kelompok yang minimum dan nilai simpangan baku antar kelompok yang maksimum. Laraswati (2014) menemukan bahwa metode average linkage dan complete linkage merupakan metode yang lebih baik diantara metode pengelompokan K-Means. Laeli (2014) menemukan bahwa metode average linkage mempunyai kinerja yang lebih baik daripada metode Ward. Berdasarkan hasil penelitian tersebut dan untuk mencapai tujuan penelitian, maka pengelompokan kabupaten/kota dilakukan dengan metode analisis cluster average linkage.

\section{Tinjauan Pustaka}

Definisi kemiskinan sesungguhnya luas maknanya, karena faktor penyebab yang kompleks, indikator maupun permasalahan lain yang ada didalamnya. Kemiskinan tidak hanya dipandang dari dimensi ekonomi, namun juga pada dimensi sosial, kesehatan, pendidikan dan berbagai dimensi lainnya. Menurut Badan Pusat Statistik (BPS), penduduk miskin yaitu penduduk hidup di bawah garis kemiskinan, atau dengan kata lain penduduk yang tidak mampu memenuhi kebutuhan dasar minimum makanan dan non makanan. Garis kemiskinan adalah besarnya nilai pengeluaran (dalam rupiah) untuk memenuhi kebutuhan dasar minimum makanan dan non makanan. Nilai garis kemiskinan yang digunakan mengacu pada kebutuhan minimum 2.100 kilo kalori per kapita per hari ditambah dengan kebutuhan minimum non makanan yang merupakan kebutuhan dasar seseorang. Kebutuhan dasar tersebut meliputi papan, sandang, 
sekolah, transportasi, serta kebutuhan rumahtangga dan individu yang mendasar lainnya. Pada penelitian ini, konsep kemiskinan mengacu pada konsep yang telah dibuat oleh BPS.

Penelitan yang terkait dengan kemiskinan sudah banyak dilakukan. Leasiwal (2013) menyebutkan bahwa kemiskinan di Maluku didominasi oleh penduduk yang tinggal di perdesaan. Adapun variabel yang secara signifikan mempengaruhi kemiskinan yakni daya beli masyarakat, inflasi, rata-rata lama sekolah, angka melek huruf, angka partisipasi kasar, angka harapan hidup, dan jumlah sekolah menengah atas. Chandra dan Nafisah (2017) dalam penelitiannya membagi wilayah Provinsi Jawa Timur ke dalam 3 kelompok kabupaten/kota. Kelompok tersebut dikategorikan ke dalam kelompok tingkat rendah, kelompok tingkat sedang dan kelompok tingkat tinggi berdasarkan faktor-faktor kemiskinan. Faktor-faktor yang digunakan yakni persentase angka melek huruf, persentase tingkat pengangguran terbuka, persentase angka partisipasi sekolah usia 16-18 tahun, dan persentase pendidikan.

Sementara Bachtiar, dkk (2016) melakukan pengkajian faktor-faktor yang mempengaruhi kemiskinan anak Balita di Provinsi Sumatera Barat. Hasil kajiannya menyebutkan beberapa faktor yang akan memberikan peluang anak balita jatuh pada kemiskinan, yaitu pendidikan yang rendah, pekerjaan ibu dan kepala rumah tangga, tinggal di wilayah perdesaan, orang tua memiliki balita lebih dari satu orang. Kemudian Kurniawan (2017) dalam penelitiannya menyebutkan bahwa faktorfaktor penyebab kemiskinan adalah pendidikan dan pendapatan.

Zuhdiyati dan Kaluge (2017) meneliti faktor-faktor yang mempengaruhi kemiskinan di Indonesia selama lima tahun terakhir yaitu 2011-2015. Penelitian ini menggunakan pendekatan kuantitatif dan regresi data panel, dengan sumber data dari Badan Pusat Statistik. Variabel yang dimasukkan dalam model meliputi Indeks Pembangunan Manusia (IPM), pertumbuhan ekonomi dan tingkat pengangguran terbuka (TPT). Hasil penelitian mereka menunjukkan bahwa yang berpengaruh terhadap kemiskinan di Indonesia adalah IPM, sedangkan pertumbuhan ekonomi dan TPT tidak berpengaruh.

Terkait dengan penelitian yang menggunakan analisis cluster, Ningsih dkk (2016) melakukan pengelompokan kabupaten/kota di Provinsi Kalimantan Timur berdasarkan data produksi palawija. Pendekatan metode yang dipakai adalah complete linkage dan average linkage. Hasilnya, terdapat 4 kelompok kabupaten/kota, yaitu kelompok pertama kabupaten/kota penghasil palawija sangat sedikit, kelompok kedua penghasil palawija cukup banyak, kelompok ketiga penghasil palawija terbanyak, dan kelompok keempat penghasil palawija sangat sedikit.

\section{METODE PENELITIAN}

\section{Sumber Data}

Data yang digunakan dalam penelitian ini adalah data sekunder yang bersumber dari Badan Pusat Statistik tahun 2017 yaitu:

$X_{1}$ : Persentase rumah tangga yang bekerja di pertanian

$X_{2}$ : Rata-rata lama sekolah

$X_{3}$ : Pengeluaran rumah tangga per kapita

$X_{4}$ : Tingkat pengangguran terbuka

Software yang digunakan untuk melakukan pengolahan adalah SPSS 22 dan STATA 13. Software SPSS digunakan untuk melakukan analisis faktor dan analisis cluster, sedangkan STATA 13 digunakan untuk membuat peta.

\section{Langkah-Langkah Analisis Data}

Dalam penelitian ini, langkah yang dilakukan dalam menghasilkan pengelompokan wilayah adalah sebagai berikut:

1. Melakukan analisis deskriptif faktor-faktor kemiskinan

2. Mengelompokkan faktor-faktor kemiskinan. Dalam analisis faktor, terlebih dahulu dilakukan pengujian adanya korelasi antar variabel dengan uji Barlett dan Kaiser- 
Meyer- Olkin (KMO) untuk kelayakan suatu data.

3. Hasil analisis faktor kemudian digunakan sebagai input untuk melakukan pengelompokan kabupaten/kota dengan metode analisis cluster average linkage.

\section{Analisis Cluster Metode Average Linkage}

Analisis merupakan teknik analisis multivariate yang digunakan untuk mengelompokkan data observasi atau variabel-variabel ke dalam cluster berdasarkan faktor-faktor yang telah ditentukan. Tujuan analisis cluster adalah mengelompokkan obyek yang mirip ke dalam satu cluster yang sama.

Metode pengelompokan (clustering) dalam analisis cluster ada 2, yaitu metode hierarki dan metode nonhirarki. Analisis hierarki, pengklusteran datanya dilakukan dengan cara mengukur jarak kedekatan pada setiap objek yang kemudian disajikan dalam bentuk dendogram. Ada beberapa macam analisis cluster dengan metode hierarki, antara lain single linkage, complete linkage, dan average linkage. Single linkage, pembentukan cluster didasarkan pada jarak terkecil. Jika dua obyek terpisah oleh jarak yang pendek maka kedua obyek tersebut akan digabung menjadi satu cluster. Complete linkage, berlawanan dengan single linkage, pengelompokkannya berdasarkan jarak terjauh. Metode average linkage menghitung jarak dua cluster yang disebut sebagai jarak rata-rata. Keuntungan metode hierarki antara lain mempercepat proses pengolahan dan menghemat waktu karena data input akan membentuk hierarki atau tingkatan sehingga mempermudah dalam penafsiran.

Dalam metode average linkage, jarak dihitung pada masing-masing cluster dengan persamaan sebagai berikut:

$d_{(u v) w}=\frac{\sum_{i} \sum_{k} d_{i k}}{V_{(u v)} N_{w}}$

Keterangan:

$d_{i k}$ : jarak objek $i$ dalam cluster $(u v)$ dan objek $k$ dalam cluster $w$.
$V_{(u v)}$ : jumlah objek dalam cluster $u v$

$N_{w}$ : jumlah objek dalam cluster $w$

\section{HASIL DAN PEMBAHASAN}

\section{Analisis deskriptif}

Analisis menggunakan

kabupaten/kota yang terletak di Pulau Jawa sebagai objek observasi. Rata-rata persentase rumah tangga miskin di kabupaten/kota sebesar 10,7 persen dengan nilai minimum 1,76 persen dan maksimum 23,56 persen. Pertanian masih menjadi mata pencaharian bagi sebagian rumah tangga di Jawa dengan rata-rata 22,88 persen, minimum 0,19 persen dan maksimum 65,58 persen. Tingkat pendidikan kepala rumah tangga di Pulau Jawa masih tergolong rendah. Tabel 1 menunjukkan rata-rata lama sekolah kepala rumah tangga sekitar 8,03 tahun atau setara dengan kelas 2 sekolah menengah pertama. Rata-rata lama sekolah minimum 4,12 tahun atau setara dengan kelas 4 SD dan maksimum 11,77 tahun atau setara dengan SMA kelas 2 atau 3. Dilihat dari pengeluaran per kapita, rata-ratanya 11.053,95 dengan nilai minimum 7.250 dan maksimum 23.098. Kecilnya pengeluaran per kapita ini menunjukkan bahwa di Pulau Jawa masih banyak rumah tangga yang belum mampu memenuhi kebutuhan hidupnya secara layak. Pengangguran di Pulau Jawa memiliki rata-rata 5,45 persen dengan nilai minimum 0,85 persen dan maksimum 13 persen. Semakin tingginya pengangguran akan berdampak pada berkurangnya pendapatan, sehingga rumah tangga akan sulit untuk hidup secara layak (lihat Tabel 1) 
Tabel 1. Deskripsi Faktor-Faktor Kemiskinan di Pulau Jawa, 2017

\begin{tabular}{|c|c|c|c|c|c|}
\hline Variabel & Observasi & Rata-Rata & Standar Deviasi & Minimum & Maksimum \\
\hline $\begin{array}{c}\text { Persentase rumah } \\
\text { tangga miskin }\end{array}$ & 119 & 10,70 & 4,64 & 1,76 & 23,56 \\
\hline $\begin{array}{c}\text { Persentase rumah } \\
\text { tangga yang bekerja di } \\
\text { pertanian }\end{array}$ & 119 & 22,88 & 17,03 & 0,19 & 65,58 \\
\hline Rata-rata lama sekolah & 119 & 8,03 & 1,65 & 4,12 & 11,77 \\
\hline $\begin{array}{c}\text { Pengeluaran rumah } \\
\text { tangga per kapita (Rp) }\end{array}$ & 119 & $11.053,95$ & $2.780,70$ & 7.250 & 23.098 \\
\hline $\begin{array}{c}\text { Tingkat Pengangguran } \\
\text { Terbuka (TPT) }\end{array}$ & 119 & 5,45 & 2,53 & 0,85 & 13,00 \\
\hline
\end{tabular}

Sumber: Badan Pusat Statistik, 2017

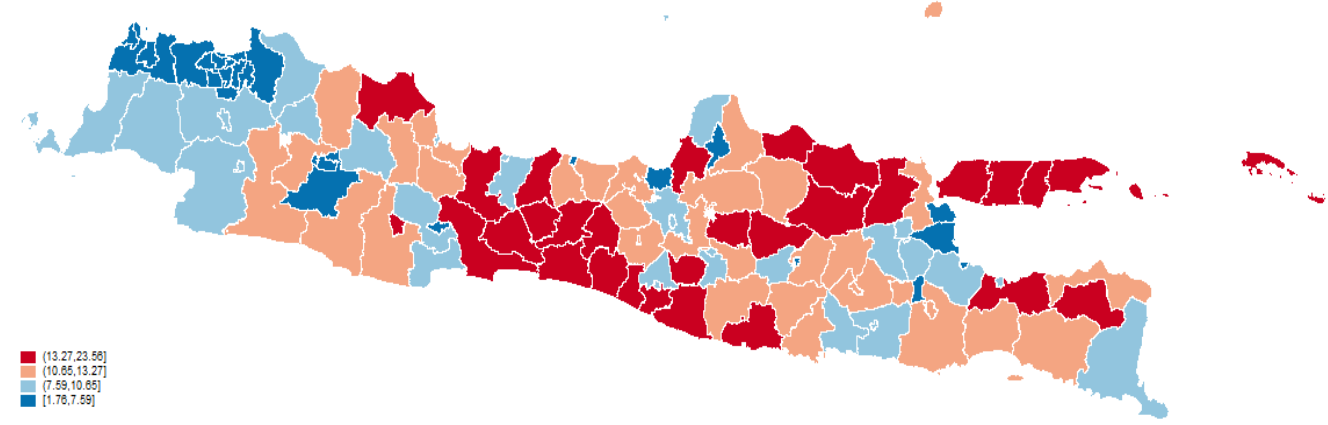

Gambar 1. Peta Wilayah Kabupaten/Kota di Pulau Jawa Berdasarkan Persentase Penduduk Miskin, 2017

\section{Persentase Penduduk Miskin di Pulau Jawa}

Gambar 1 menunjukkan peta wilayah berdasarkan persentase penduduk miskin di Pulau Jawa. Warna biru tua tua menunjukkan kabupaten/kota dengan persentase penduduk miskin paling rendah. Warna biru muda menunjukkan kabupaten/kota dengan persentase penduduk miskin cukup rendah. Warna merah muda menunjukkan kabupaten/kota dengan persentase penduduk miskin cukup tinggi dan warna merah tua menunjukkan kabupaten/kota dengan persentase penduduk miskin paling tinggi. Kabupaten/kota yang memiliki persentase penduduk miskin tertinggi (dalam peta ditunjukkan dengan warna merah tua) adalah sebagai berikut:

1. Provinsi Jawa Barat: Kabupaten Kuningan, Kabupaten Indramayu, dan Kota Tasikmalaya.
2. Provinsi Jawa Tengah: Kabupaten Grobogan, Kabupaten Demak, Kabupaten Purworejo, Kabupaten Cilacap, Kabupaten Sragen, Kabupaten Klaten, Kabupaten Banyumas, Kabupaten Banjarnegara, Kabupaten Pemalang, Kabupaten Rembang, Kabupaten Brebes, Kabupaten Kebumen, Kabupaten Purbalingga, dan Kabupaten Wonosobo.

3. Provinsi Yogyakarta: Kabupaten Bantul, Kabupaten Gunung Kidul, dan Kabupaten Kulon Progo.

4. Provinsi Jawa Timur: Kabupaten Bojonegoro, Kabupaten Lamongan, Kabupaten Bondowoso, Kabupaten Ngawi, Kabupaten Pacitan, Kabupaten Pamekasan, Kabupaten Tuban, Kabupaten Sumenep, Kabupaten Probolinggo, Kabupaten Bangkalan, dan Kabupaten Sampang.

Persentase Penduduk yang Bekerja di Pertanian 


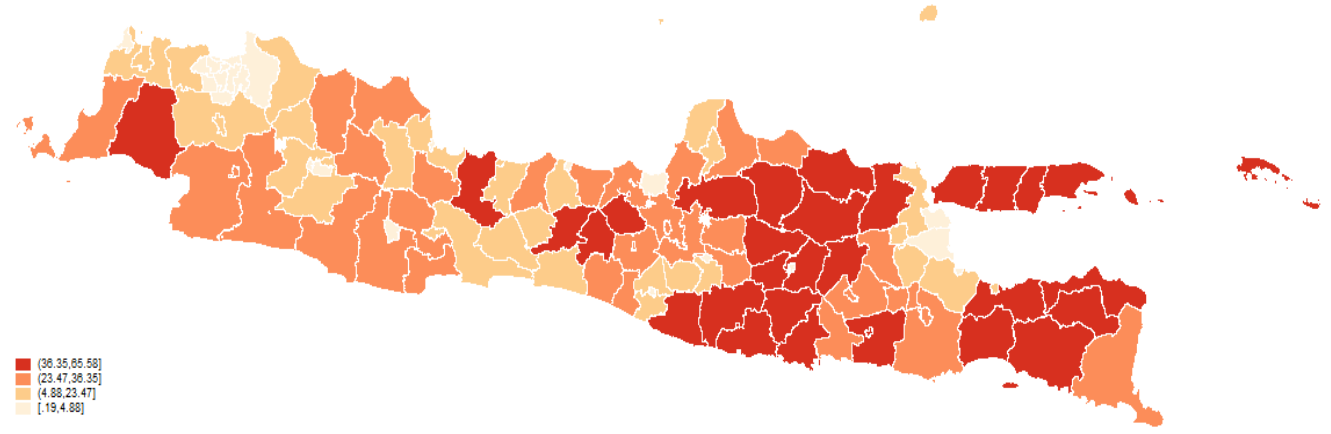

Gambar 2. Peta Wilayah Kabupaten/Kota di Pulau Jawa Berdasarkan Persentase Penduduk yang Bekerja di Pertanian, 2017

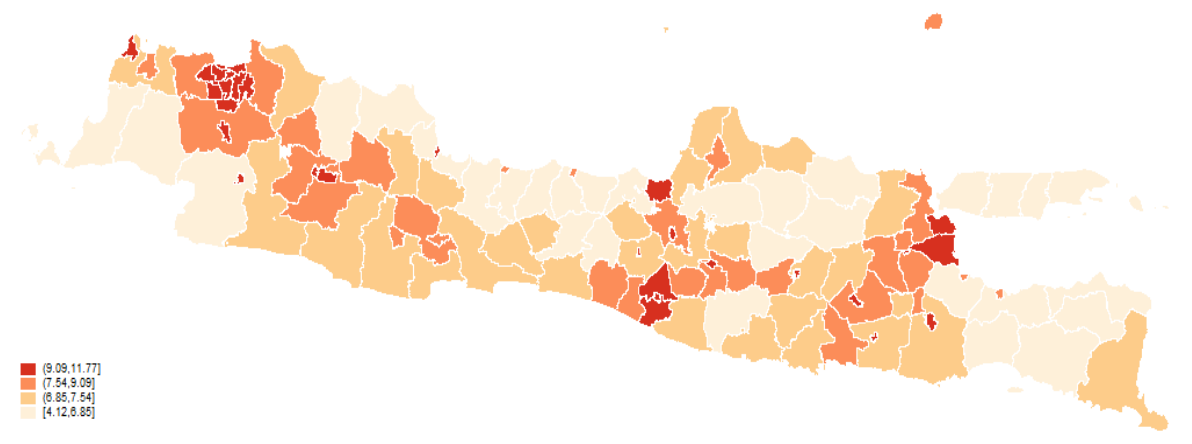

Gambar 3. Peta Wilayah Kabupaten/Kota di Pulau Jawa Berdasarkan Rata-Rata Lama Sekolah, 2017

Penduduk yang bekerja di sektor pertanian di Pulau Jawa ditunjukkan dalam peta pada Gambar 2. Semakin tua warnanya semakin tinggi persentase penduduk yang bekerja di sektor pertanian. Kabupaten dengan persentase penduduk yang bekerja di sektor pertanian pada kelompok tertinggi adalah sebagai berikut:

\section{Provinsi Jawa Banten: Kabupaten Lebak.}

2. Provinsi Jawa Tengah: Kabupaten Wonosobo, Kabupaten Brebes, Kabupaten Wonogiri, Kabupaten Grobogan, Kabupaten Temanggung, dan Kabupaten Blora

3. Provinsi Yogyakarta: Kabupaten Gunung Kidul.

4. Provinsi Jawa Timur: Kabupaten Jember, Kabupaten Tuban, Kabupaten Malang, Kabupaten Magetan, Kabupaten Lamongan, Kabupaten Nganjuk, Kabupaten Lumajang, Kabupaten Probolinggo, Kabupaten Ponorogo, Kabupaten Madiun, Kabupaten Situbondo, Kabupaten Blitar, Kabupaten Bondowoso, Kabupaten Bojonegoro, Kabupaten
Trenggalek, Kabupaten Ngawi, Kabupaten Bangkalan, Kabupaten Pamekasan, Kabupaten Pacitan, Kabupaten Sumenep dan Kabupaten Sampang. Bahkan di Kabupaten Bangkalan, Kabupaten Pamekasan, Kabupaten Pacitan, Kabupaten Sumenep dan Kabupaten Sampang lebih dari separuh penduduknya bekerja di sektor pertanian (lihat Gambar 2)

\section{Rata-Rata Lama Sekolah Penduduk di Pulau Jawa}

Rata-rata lama sekolah menggambarkan rata-rata tingkat pendidikan yang dicapai oleh penduduk di suatu wilayah. Gradasi warna yang disajikan dalam peta pada Gambar 3 menggambarkan rata-rata lama sekolah di kabupaten/kota, dengan penjelasan semakin gelap warnanya semakin banyak jumlah tahun rata-rata lama sekolah. Jika dicermati dari peta tersebut, rata-rata lama sekolah di Pulau Jawa masih rendah. Kabupaten Sampang memiliki rata-rata lama sekolah terendah (4,12 tahun) dan Kota Tangerang Selatan memiliki rata-rata lama sekolah 


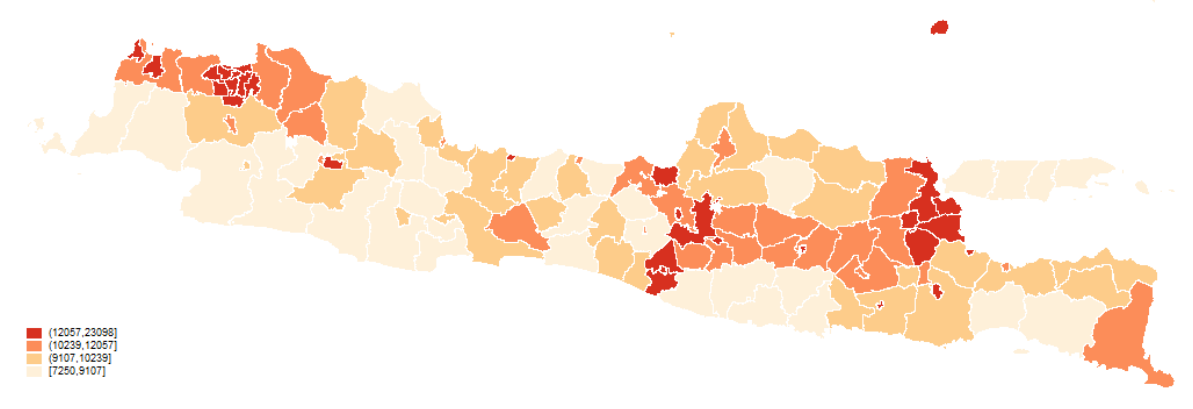

Gambar 4. Peta Wilayah Kabupaten/Kota di Pulau Jawa Berdasarkan Pengeluaran per Kapita, 2017

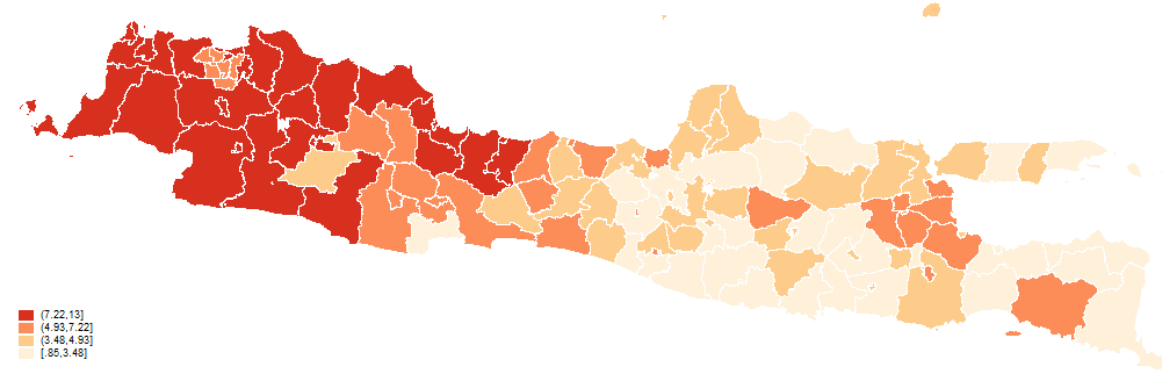

Gambar 5. Peta Wilayah Kabupaten/Kota di Pulau Jawa Berdasarkan Tingkat Pengangguran Terbuka, 2017

tertinggi (11,77 tahun). Kabupaten/Kota dengan warna tua yang artinya memiliki rata-rata lama sekolah lebih tinggi dibanding kabupaten/kota lainnya, adalah sebagai berikut:

1. Provinsi Banten: Kota Tangerang, Kota Cilegon, dan Kota Tangerang Selatan.

2. Provinsi DKI Jakarta: Kota Jakarta Barat, Kota Jakarta Utara, Kota Jakarta Selatan, dan Kota Jakarta Timur.

3. Provinsi Jawa Barat: Kota Sukabumi, Kota Cirebon, Kota Bogor, Kota Bandung, Kota Depok, Kota Bekasi, dan Kota Cimahi.

4. Provinsi Jawa Tengah: Kota Salatiga, Kota Magelang, Kota Surakarta, Kota Semarang,

5. Provinsi Yogyakarta: Kabupaten Bantul dan Kabupaten Sleman

6. Provinsi Jawa Timur: Kota Pasuruan, Kota Blitar, Kota Kediri, Kota Mojokerto, Kota Malang, Kabupaten Sidoarjo, dan Kota Surabaya.

\section{Pengeluaran rumah tangga per kapita}

Pengeluaran rumah tangga per kapita menggambarkan rata-rata pengeluaran setiap penduduk di suatu wilayah. Semakin besar pengeluaran per kapita diartikan semakin tinggi tingkat kesejahteraan penduduk. Di Pulau Jawa, rata-rata pengeluran per kapita penduduknya sebesar 11.054 rupiah, artinya setiap penduduk memenuhi kebutuhannya baik makanan maupun non makanan sebesar 11.054 rupiah per bulan. Pengeluaran per kapita terndah di Kabupaten Tasikmalaya (7.250 rupiah), dan yang tertinggi di Kota Jakarta Selatan (23.098 rupiah). Kabupaten/kota dengan pengeluaran per kapita lebih tinggi dari kabupaten/kota lainnya ditunjukkan dalam gambar peta yang berwarna paling tua. Kabupaten/kota tersebut adalah sebagai berikut:

1. Provinsi Banten: Kota Cilegon, Kota Serang, Kota Tangerang, dan Kota Tangerang Selatan.

2. Provinsi DKI Jakarta: Kota Jakarta Pusat, Kota Jakarta Timur, Kota Jakarta Utara, Kota Jakarta Barat, dan Kota Jakarta Selatan.

3. Provinsi Jawa Barat: Kota Depok, Kota Bekasi, dan Kota Bandung.

4. Provinsi Jawa Tengah: Kabupaten Boyolali, Kota Tegal, Kota Surakarta, Kota Semarang, dan Kota Salatiga.

5. Provinsi Yogyakarta: Kabupaten Bantul, Kabupaten Sleman, dan Kota Yogyakarta. 
Tabel 2. Hasil Uji KMO dan Bartlett

Kaiser-Meyer-Olkin Measure of Sampling Adequacy.

Bartlett's Test of Sphericity Approx. Chi-Square

df

Sig.

Tabel 3. Total Variance Explained

\begin{tabular}{|c|c|c|c|c|c|c|}
\hline \multirow{2}{*}{ Component } & \multicolumn{3}{|c|}{ Initial Eigenvalues } & \multicolumn{3}{c|}{ Extraction Sums of Squared Loadings } \\
\cline { 2 - 7 } & Total & \% of Variance & Cumulative \% & Total & $\%$ of Variance & Cumulative \% \\
\hline 1 & 2.725 & 68.135 & 68.135 & 2.725 & 68.135 & 68.135 \\
2 & .923 & 23.086 & 91.221 & & & \\
3 & .256 & 6.399 & 97.620 & & & \\
\hline 4 & .095 & 2.380 & 100.000 & & & \\
\hline
\end{tabular}

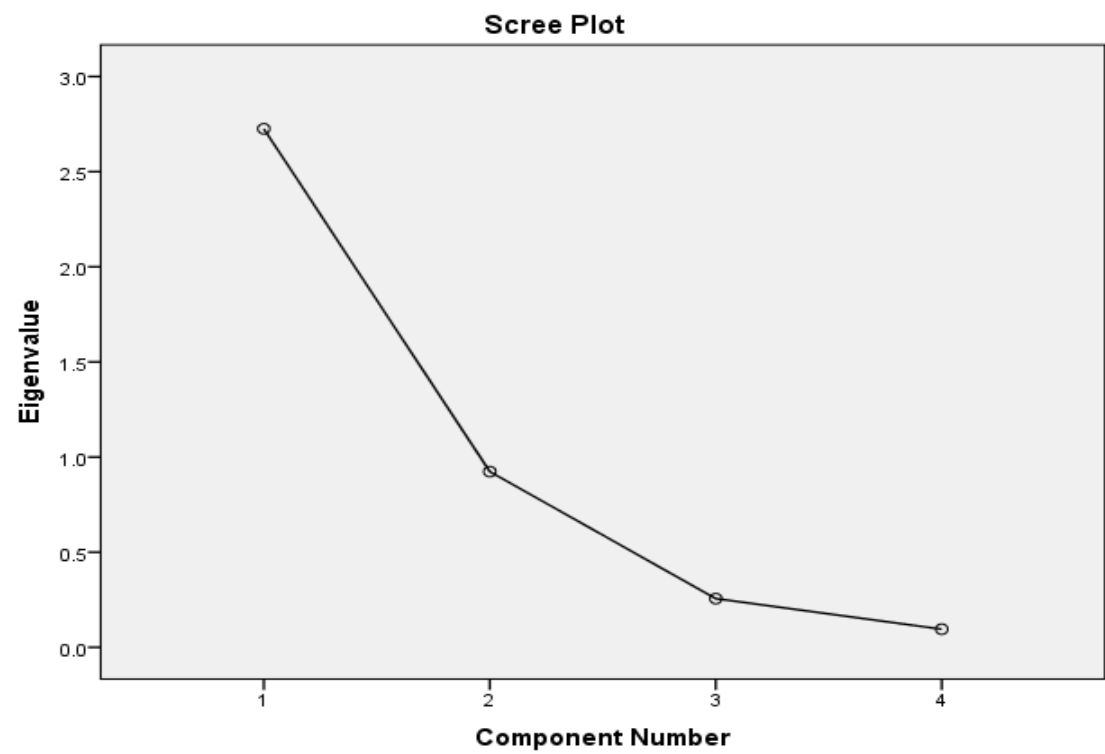

Gambar 6. Scree Plot

6. Provinsi Jawa Timur: Kota Batu, Kabupaten Mojokerto, Kabupaten Gresik, Kota Pasuruan, Kota Mojokerto, Kota Blitar, Kabupaten Sidoarjo, Kota Madiun, Kota Malang, dan Kota Surabaya.

\section{Tingkat Pengangguran Terbuka}

Menurut BPS, pengangguran adalah persentase jumlah pengangguran terhadap jumlah angkatan kerja. Gambar 5 menggambarkan peta wilayah berdasarkan tingkat pengangguran terbuka. Gradasi warna menjelaskan bahwa semakin tua warna suatu wilayah maka semakin tinggi tingkat pengangguran terbuka di wilayah tersebut. Kabupaten dengan tingkat pengangguran terendah di Pacitan, sedangkan yang tertinggi di Kabupaten Serang. Beberapa kabupaten/kota yang memilki tingkat pengangguran terbuka lebih tinggi dibanding kabupaten/kota lainnya digambarkan dalam peta dengan warna yang paling tua. Kabupaten/kota tersebut adalah:

1. Provinsi Banten: Kabupaten Pandeglang, Kota Serang, Kabupaten Lebak, Kabupaten Tangerang, Kota Cilegon, dan Kabupaten Serang.

2. Provinsi DKI Jakarta: Kota Jakarta Pusat dan Kota Jakarta Utara.

3. Provinsi Jawa Barat: Kabupaten Sukabumi, Kabupaten Garut, Kabupaten Kuningan, Kota Sukabumi, Kota Cimahi, Kota Bandung, Kabupaten Indramayu, Kabupaten Subang, Kabupaten Purwakarta, Kota 


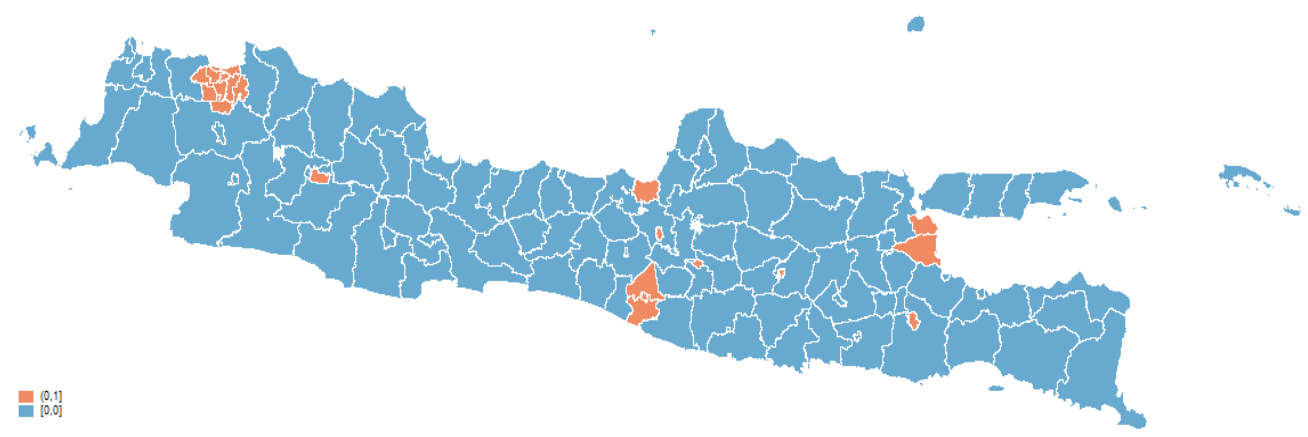

Gambar 7. Peta Pengelompokan Wilayah Berdasarkan Faktor-Faktor Kemiskinan

Cirebon, Kota Bekasi, Kabupaten

Bandung Barat, Kabupaten Bogor, Kabupaten Karawang, Kota Bogor, Kabupaten Cirebon, Kabupaten Cianjur, Kabupaten Bekasi,

4. Provinsi Jawa Tengah: Kabupaten Tegal, Kabupaten Brebes, dan Kota Tegal.

5. Provinsi Jawa Timur: Kota Malang.

\section{Analisis Faktor}

Sebelum melakukan pengelompokan terlebih dahulu dilakukan uji KMO dan Bartlett untuk menguji apakah terdapat korelasi yang signifikan antar variabel. Variabel yang memiliki korelasi yang tinggi akan di reduksi.

Dari hasil pengujian KMO dan Bartlett, diperoleh p-value sebesar 0,000 sehingga tolak $\mathrm{H} 0$, artinya terdapat korelasi antar variabel. Selanjutnya, dilakukan uji KMO untuk mengetahui kecukupan data untuk analisis faktor. Hasil uji KMO menunjukkan besarnya KMO sebesar 0,645 sehingga nilai $\mathrm{KMO}>0,5$ yang artinya analisis faktor cukup baik untuk dilakukan (Sharma, 1996). Tujuan dari analisis faktor ini untuk menyederhanakan kumpulan 4 variabel yang digunakan sebagai faktorfaktor kemiskinan (Tabel 2).

Jumlah faktor yang akan dibentuk ditentukan dengan beberapa kriteria agar diperoleh faktor-faktor yang sesuai. Kriteria pertama yang digunakan sebagai penentu jumlah faktor adalah eigen value. Faktor yang memiliki eigen value lebih dari 1 adalah faktor 1 , tetapi karena persentase cumulative eigen value yang mencapai lebih dari 90 persen di faktor 2, maka jumlah faktor yang digunakan adalah dua (Tabel 3).

Penentuan jumlah faktor juga bisa menggunakan scree plot. Scree plot merupakan nilai plot eigen value terhadap jumlah faktor yang diekstraksi. Titik pada tempat dimana scree mulai terjadi menunjukkan banyaknya faktor yang sesuai, dimana scree terlihat mulai mendatar. Berdasarkan scree plot pada Gambar 6 dapat disimpulkan bahwa garis mulai mendatar di titik 3 sehingga hanya 2 faktor yang akan digunakan untuk membentuk cluster. Hasil ini sejalan dengan pembentukan faktor menggunakan PCA pada Tabel 3.

\section{Analisis Cluster}

Hasil dari analisis faktor digunakan sebagai input dalam melakukan analisis cluster. Hasil analisis cluster dengan metode average linkage membagi kabupaten/kota di Pulau Jawa menjadi 2 kelompok. Penentuan kelompok didasarkan pada Gambar dendogram seperti yang tersaji dalam Gambar 8.

Kelompok I merupakan kelompok kabupaten/kota yang kemiskinannya rendah, terdiri dari:

1. Provinsi Banten: Kota Tangerang dan Kota Tangerang Selatan.

2. Provinsi DKI Jakarta: Kota Jakarta Barat, Kota Jakarta Selatan, Kota Jakarta Timur, Kota Jakarta Pusat, dan Kota Jakarta Utara.

3. Provinsi Jawa Barat: Kota Bandung, Kota Depok, dan Kota Bekasi.

4. Provinsi Jawa Tengah: Kota Semarang, Kota Salatiga, dan Kota Surakarta. 

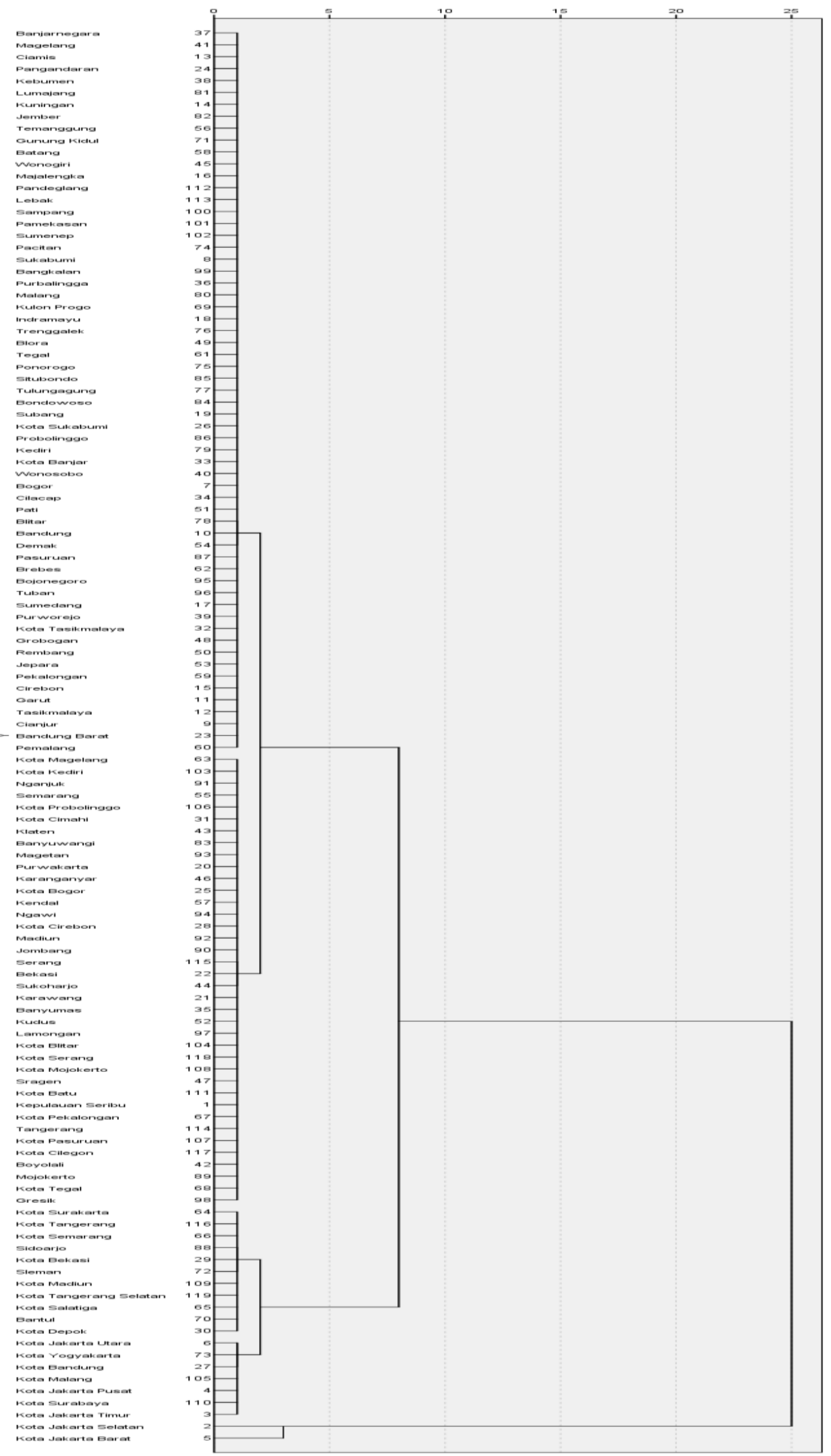

Gambar 8. Dendogram using Average Linkage (Between Group)
5. Provinsi
Yogyakarta:
Kota
6. Provinsi Jawa Timur: Kota Surabaya, Yogyakarta, Kabupaten Bantul, dan Kota Malang, Kota Madiun, dan Kabupaten Sleman. Kabupaten Sidoarjo. 
Sedangkan kelompok 2 terdiri dari kabupaten/kota yang tingkat kemiskinannya lebih tinggi, yaitu sebanyak 99 kabupaten/kota, terdiri dari:

1. Provinsi Banten: Kabupaten Cilegon, Kabupaten Serang, Kabupaten Tangerang, Kota Serang, Kabupaten Lebak, dan Kabupaten Pandeglang.

2. Provinsi DKI Jakarta: Kabupaten Kepulauan Seribu.

3. Provinsi Jawa Barat: Kabupaten Bekasi, Kota Bogor, Kabupaten Bandung, Kota Cimahi, Kabupaten Sukabumi, Kabupaten Ciamis, Kota Sukabumi, Kabupaten Bogor, Kabupaten Purwakarta, Kota Cirebon, Kabupaten Pangandaran, Kabupaten Karawang, Kabupaten Sumedang, Kabupaten Subang, Kabupaten Tasikmalaya, Kabupaten Garut, Kabupaten Cianjur, Kabupaten Bandung Barat, Kabupaten Majalengka, Kabupaten Cirebon, Kabupaten Kuningan, Kabupaten Indramayu, dan Kota Tasikmalaya.

4. Provinsi Jawa Tengah: Kota Banjar, Kota Pekalongan, Kabupaten Kudus, Kabupaten Semarang, Kota Tegal, Kabupaten Jepara, Kabupaten Sukoharjo, Kota Magelang, Kabupaten Tegal, Kabupaten Batang, Kabupaten Kendal, Kabupaten Pati, Kabupaten Temanggung, Kabupaten Boyolali, Kabupaten Karanganyar, Kabupaten Magelang, Kabupaten Pekalongan, Kabupaten Wonogiri, Kabupaten Blora, Kabupaten Grobogan, Kabupaten Demak, Kabupaten Purworejo, Kabupaten Cilacap, Kabupaten Sragen, Kabupaten Klaten, Kabupaten Banyumas, Kabupaten Banjarnegara, Kabupaten Pemalang, Kabupaten Rembang, Kabupaten Purbalingga, Kabupaten Brebes, Kabupaten Kebumen, dan Kabupaten Wonosobo.

5. Provinsi Yogyakarta: Kabupaten Gunung Kidul, dan Kabupaten Kulon Progo.

6. Provinsi Jawa Timur: Kota Batu, Kota Mojokerto, Kota Pasuruan, Kota Probolinggo, Kota Blitar, Kabupaten
Tulungagung, Kota Kediri, Kabupaten Banyuwangi, Kabupaten Blitar, Kabupaten Mojokerto, Kabupaten Pasuruan, Kabupaten Jombang, Kabupaten Magetan, Kabupaten Lumajang, Kabupaten Jember, Kabupaten Malang, Kabupaten Ponorogo, Kabupaten Nganjuk, Kabupaten Kediri, Kabupaten Madiun, Kabupaten Gresik, Kabupaten Trenggalek, Kabupaten Situbondo, Kabupaten Bojonegoro, Kabupaten Lamongan, Kabupaten Bondowoso, Kabupaten Ngawi, Kabupaten Pacitan, Kabupaten Pamekasan, Kabupaten Tuban, Kabupaten Sumenep, Kabupaten Probolinggo, Kabupaten Bangkalan, dan Kabupaten Sampang.

Penyajian kelompok kabupaten/kota hasil clustering tersaji dalam bentuk peta yang ditunjukkan pada Gambar 7.

\section{KESIMPULAN DAN SARAN}

Dari hasil pembahasan diperoleh kesimpulan bahwa dengan berdasarkan faktor-faktor kemiskinan, kabupaten/kota di Pulau Jawa dapat dibagi ke dalam dua kelompok. Sebanyak 16,8 persen kabupaten/kota di Pulau Jawa masuk dalam kelompok pertama, dan sisanya sebanyak 83,2 persen masuk ke dalam kelompok kedua. Kelompok pertama terdiri dari 20 kabupaten/kota, yaitu:

1. Provinsi Banten: Kota Tangerang dan Kota Tangerang Selatan.

2. Provinsi DKI Jakarta: Kota Jakarta Barat, Kota Jakarta Selatan, Kota Jakarta Timur, Kota Jakarta Pusat, dan Kota Jakarta Utara.

3. Provinsi Jawa Barat: Kota Bandung, Kota Depok, dan Kota Bekasi.

4. Provinsi Jawa Tengah: Kota Semarang, Kota Salatiga, dan Kota Surakarta.

5. Provinsi Yogyakarta: Kota Yogyakarta, Kabupaten Bantul, dan Kabupaten Sleman.

6. Provinsi Jawa Timur: Kota Surabaya, Kota Malang, Kota Madiun, dan Kabupaten Sidoarjo.

Sedangkan 99 kabupaten/kota lainnya termasuk dalam kelompok kedua. 
Kelompok I merupakan kabupaten/kota yang tingkat kemiskinannya rendah, sedangkan kelompok II merupakan kabupaten/kota yang tingkat kemiskinannya tinggi. Saran, penelitian berikutnya dapat meneliti lebih lanjut pengaruh dari masing-masing faktor kemiskinan terhadap tingkat kemiskinan di setiap kelompok.

\section{DAFTAR PUSTAKA}

Bachtiar, N., Rasbi, M.J., dan Fahmi, R. (2016). Analisis Kemiskinan Anak Balita pada Rumah Tangga di Provinsi Sumatera Barat. Jurnal Kependudukan Indonesia Vol. 11 No. 1 Juni 2016, hal. 29-38.

Barakbah, A.R., dan Arai, K. (2004). Determining Constrains of Moving Variance to Find Global Optimum and Make Automatic Clustering. Proc. Industrial Electronics Seminar (IES) 2004, pp.409-413, October 12, 2004, Surabaya, Indonesia

Bappenas. (2014). Penyusunan Rencana Pembangunan Jangka Menengah Nasional 2015-2019. Kementerian Perencanaan Pembangunan Nasional/Badan Perencanaan Pembangunan Nasional. Jakarta.

Badan Pusat Statistik. (2017). Data dan Informasi Kemiskinan Kabupaten/Kota 2017. Badan Pusat Statistik. Jakarta. Diakses pada https://www.bps.go.id/

Chandra, N.E., dan Nafisah, Q. (2017). Analisis Cluster Average Linkage Berdasarkan Faktor-Faktor Kemiskinan di Provinsi Jawa Timur. Zeta-Math Journal Volume 3 No. 2, November 2017.

Kurniawan M.DP. (2017). Analisis FaktorFaktor Penyebab Kemiskinan di Kabupaten Musi Banyuasin (Studi Kasus di Kecamatan Sungai Lilin). Jurnal Ilmu Ekonomi Global Masa Kini Volume 8 No. 01 Juli 2017.

Laraswati, T.F., (2014). Perbandingan Kinerja Metode Complete Linkage, Metode Average Linkage, dan Metode K-Means dalam Menentukan Hasil Analisis Cluster. Skripsi. Fakultas
Matematika dan Ilmu Pengetahuan Alam. Universitas Negeri Yogayakarta. 2014

Leasiwal, T.C. (2013). Determinan Kemiskinan dan Karakteristik Kemiskinan di Provinsi Maluku. Jurnal Ekonomi, Cita Ekonomika, Vol. VII, No. 2, Desember 2013, ISSN: 1978-3612.

Ningsih, S., Wahyuningsih, S., dan Nasution, Y.N. (2016). Perbandingan Kinerja Metode Complete Linkage dan Average Linkage dalam Menentukan Hasil Analisis Cluster. Prosiding Seminar Sains dan Teknologi FMIPA Unmul, Vol. 1 No. 1 Juli 2016, Samarinda, Indonesia.

Sharma, S. (1996). Applied Multivariate Techniques, New York: John Wiley $\&$ Sons, Inc.

Zuhdiyati, N. dan Kaluge, D. (2017). Analisis Faktor-Faktor yang Mempengaruhi Kemiskinan di Indonesia Selama Lima Tahun Terakhir (Studi Kasus pada 33 Provinsi). JIBEKA, Volume 11 No. 2 Februari 2017: 27-31 